\title{
Assessment of radionuclide contamination in the Black Sea using POSEIDON/RODOS system
}

\author{
B. Veleva, L. Koziy ${ }^{1}$, S. Yushchenko ${ }^{1}$, V. Maderich ${ }^{1}$ and G. Mungov \\ NIMH-BAS, 66 Tzarigradsko Ch., 1784 Sofia, Bulgaria \\ ${ }^{1}$ IMMSP, Glushkova Pr. 42, 03187 Kiev, Ukraine
}

\begin{abstract}
The coupled system of the 3D hydrodynamical model THREETOX and the radiological box model POSEIDON-R, developed in the framework of the European system RODOS for emergency response to a nuclear accident, was applied to the Black Sea for reconstruction and outlook of the radionuclide contamination in result of bomb testing and the Chernobyl accident. For the model verification hydrophysical data was obtained from historical records of up to 15180 observational stations in the Black Sea. The data was grouped by months in $1^{\circ}$ by $1^{\circ}$ spatial squares and homogenised in the vertical with application of the method of Reininger and Ross. The radiological data was derived from literature sources mainly based on the expeditions of "Typhoon", IBSS, MHI, Hydrometeorological service (all from the former USSR), "K. Piri" and "Knorr" (US-Turkish) expeditions in the Black Sea. The vertical radionuclide stratification was obtained as one profile "mean for the whole sea" due to the scarce data. The spatial reconstruction of the hydrophyscal and radiological fields were done by gridding of the arbitrarily spaced data applying the method of "splines in tension" and eliminating aliasing by the median method. The THREETOX model was used for re-analysis of radionuclide transport. The ${ }^{137} \mathrm{Cs}$ concentrations calculated with POSEIDON-R in water and biota are compared with the collected data. A good agreement was found due to the implemented dynamic food chain model.
\end{abstract}

\section{INTRODUCTION}

The Black Sea, along with the Baltic Sea was strongly affected by the Chernobyl accident. The radioactive contamination in the Black Sea waters as well as its post-Chernobyl evolution were studied using different approaches but still not covering sufficiently all directions of impact and relative details. There is lack of comparable and systematically collected data for the whole basin. The available data is from several expeditions done after the Chernobyl accident organized by institutions from the former USSR - "Typhoon", IBSS, MHI, Hydro-meteorological service as well as several American-Turkish expeditions on the RV "K. Piri" and "Knorr". None of them covered the entire area of the basin. The data from the deeper layers (below the surface) were very irregular and scarce. The RER/2003 IAEA TC Project "Marine Environmental Assessment of the Black Sea Region" marked a promising start allowing prediction of a broader and comparable data set.

The consequences of the Chernobyl accident for the entire coast of Europe revealed the necessity to study the radioactive contamination and its time-spatial evolution. The coupled system of 3D hydrodynamical model THREETOX and radiological box model POSEIDON/RODOS , developed in the framework of the European system RODOS for emergency response to nuclear accident $[1,2]$, was applied to the Black Sea for reconstruction and estimation of ${ }^{137} \mathrm{Cs}$ and ${ }^{90} \mathrm{Sr}$ contamination in result of bomb testing and the Chernobyl accident.

\section{DATA AND FIELDS RECONSTRUCTION}

The Black Sea is a landlocked sea connected with other sea basins via the narrow and shallow Turkish straits. Long-term estuary type circulation is essentially driven by the freshwater surplus and exchange with the Mediterranean Sea. It is the world's largest anoxic basin and it is also widely known for its particular circulation pattern and strong stratification due to its positive water balance of the sea, restricted water exchange with the adjacent seas and specific topographic conditions. Specific features of the Black Sea are the Cold Intermediate Layer (CIL) and the relatively permanent halocline having strong influence over the circulation, water exchange and the distribution of all contaminants [3, 4]. The penetration of the surface waters into the deeper part of the sea is due to the sinking of the Mediterranean waters and to the entrained waters from CIL.

The cyclonic circulation controls the basin-wide transfer and distribution of soluble radionuclides supplied by river input, their vertical migration due to the mixing between surface and deeper waters, and the phytoplankton-mediated deposition of particle-reactive radionuclides. Recent studies based on highresolution numerical models [4] showed that the topography, wind stress, surface and lateral buoyancy 
fluxes mainly contribute to the driving of the Black Sea general circulation. With seasonal forcing the specific features of the basic circulation are better resolved in addition to the reproduced seasonal cycle.

The contamination of the Black Sea with man-made radionuclides is formed as a result of the tho main sources: global fallout from the nuclear weapon tests in the atmosphere (forming a more homogeneous long term contamination) and the Chernobyl accident in April 1986. The Chernobyl accident formed a very inhomogeneous contamination field with a great number of different radionuclides. Among them ${ }^{137} \mathrm{Cs}$ and ${ }^{90} \mathrm{Sr}$ are well recognised as the most important because of their high degree of contamination, radiobiological importance and long half-life times.

\subsection{Data}

Hydrophysical and radiological data were collected for the verification of the models. The hydrophysiral data were taken from: World Ocean Data set 1998 (WOD'98); 8 NATO expeditions in the Black Sea, HydroBlack'91, ComsBlack'93, HydroBlack'93 international expeditions, "Black Sea GIS" CD (BSEP); and additional institutional data. Procedures for quality control given in [5], were used. The final data set after eliminating the duplicated and replicated stations was up to 15180 stations. They were grouped by months in $1^{\circ}$ by $1^{\circ}$ spatial squares. The interpolation in the vertical was done with the application the method of Reininger and Ross - [5]. Where necessary spatial interpolation by the gridding method of the arbitrarily spaced data applying "splines in tension" was used with eliminating aliasing by the median method. The monthly mean values on the standard oceanographic levels were verified with the "Black Sea GIS" data and with other literature sources.

The radiological data were derived from literature sources based mainly on the expeditions of "Typhoon", IBSS, MHI, Hydrometeorological service (all form the former USSR), and from the US. Turkey expeditions on RV "K. Piri" and "Knorr" in the Black Sea [3, 6-8]. The vertical radionuclite stratification was obtained as one "mean for the whole sea" vertical profile due to the lack of empirical data for the deep layers.

\subsection{Fields reconstruction}

The spatial reconstruction was performed by gridding of the arbitrarily spaced radioactivity data applying again the "splines in tension" method and eliminating aliasing by the median method. Inventory estimation based on the reconstructed fields of ${ }^{137} \mathrm{Cs}$ and ${ }^{90} \mathrm{Sr}$ show good agreement with the known values in the literature. Thus the interpolation procedure is considered as adequate. For example, the inventory of soluble ${ }^{137} \mathrm{Cs}$ due to the Chernobyl atmospheric fallout based on the reconstructed field of concentrations is estimated as $1.667 * 10^{15} \mathrm{~Bq}(+50 \% ;-15 \%)$ This value is in a good agreement with the estimations given in $[9,10]$ and it is less then $2,804 * 10^{15} \mathrm{~Bq}$, the value proposed in [11]. The reconstructed climatic temperature and salinity fields are shown on Fig.1 and Fig.2. ${ }^{137} \mathrm{Cs}$ and ${ }^{90} \mathrm{Sr}$ surface water concentrations for June 1986 are presented on Figure 3.

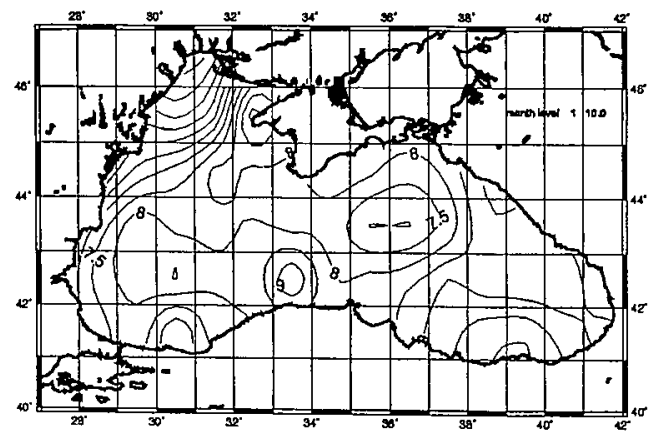

a) January

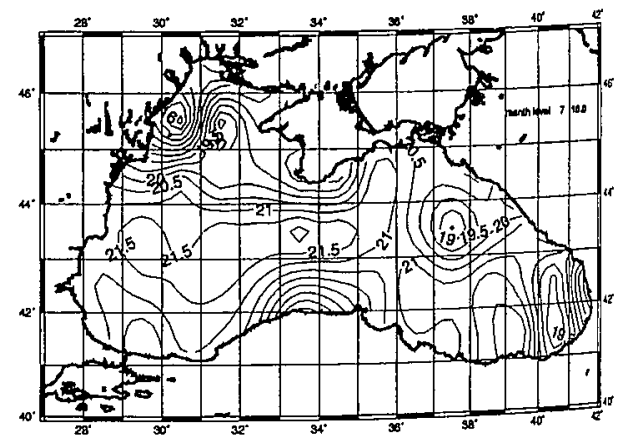

b) July

Figure 1. Average monthly field of the water temperature $\mathrm{T}\left({ }^{\circ} \mathrm{C}\right), 10 \mathrm{~m}$ 


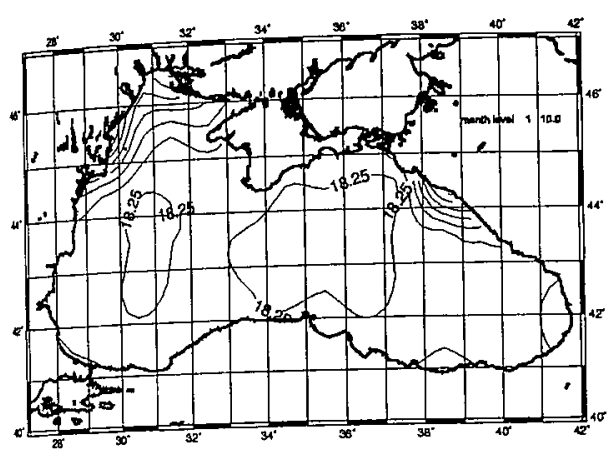

a) January

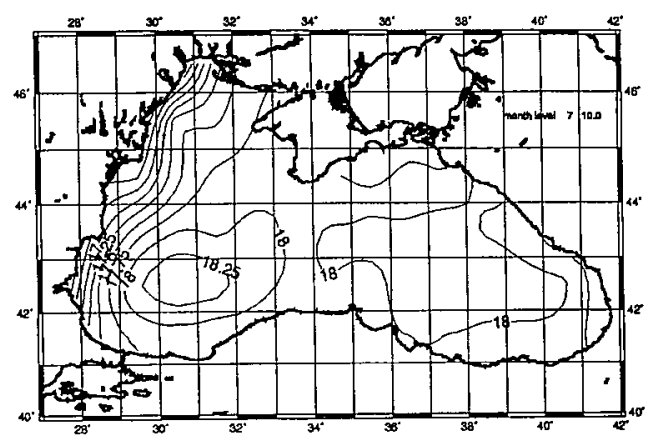

b) July

Figure 2. Average monthly field of the salinity $\mathrm{S}(\%), 10 \mathrm{~m}$

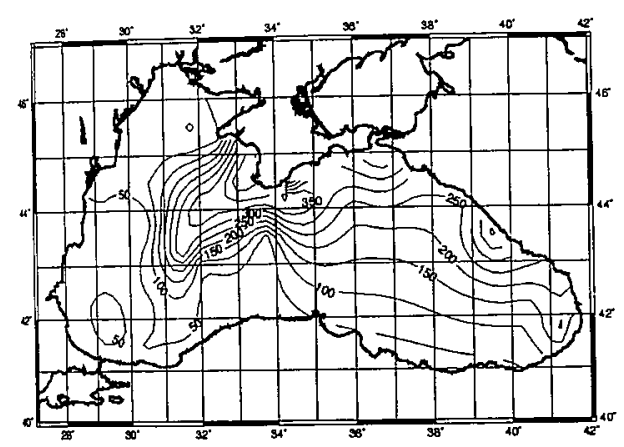

a) ${ }^{137} \mathrm{Cs}$ in June

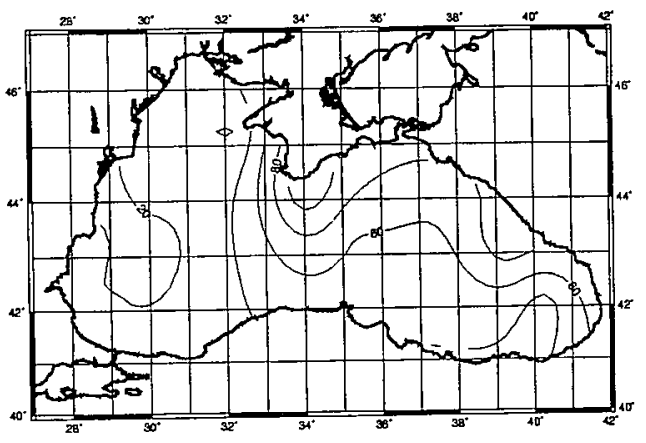

b) ${ }^{90} \mathrm{Sr}$ in May-June

Figure 3. Reconstructed fields of ${ }^{137} \mathrm{Cs}$ and ${ }^{90} \mathrm{Sr}$ surface concentrations $\left(\mathrm{Bq} / \mathrm{m}^{3}\right)$ in 1986

\section{THREETOX AND POSEIDON-R MODELS}

\subsection{THREETOX hydrodynamic model}

The THREETOX code [12] in POSEIDON-R system is intended for (i) calculation of the water exchange rates between the compartments in the box model and for (ii) simulation of the short-term transport and fate of the radionuclides. THREETOX includes a set of submodels: a hydrodynamics submodel, suspended sediment transport and radionuclide transport submodels.

The hydrodynamics is simulated on the basis of the three-dimensional, time-dependent, free surface, primitive equation POM model [13]. The prognostic variables of the hydrodynamics code are the three components of the velocity, temperature, salinity and surface elevation. Suspended sediment transport is described by the advection-diffusion equations, taking into account fall velocities of the sediment grains. The bottom boundary condition describes sediment resuspension or settling down depending on the ratio between the equilibrium and actual near bottom suspended sediment concentration. The thickness of the upper layer of the bottom deposition is governed by the equation of the bottom deformation.

The equations of the radionuclide transport describe the concentration of the radionuclides in solution, and the concentration in suspended and bottom sediments. The exchanges between these forms have been described as adsorption-desorption and sedimentation-resuspension processes. Adsorption and desorption of radionuclides between liquid and solid phases are described by the radionuclide exchange rates $a_{1,2}{ }^{w}, a_{1,2}{ }^{b}$, and by the distribution coefficients $K_{d}{ }^{w}, K_{d}{ }^{b}$. 


\subsection{POSEIDON-R radiological model}

The model "POSEIDON-R" is based on an initially developed by CEPN [14] box (compartment) model. In the frame of the POSEIDON project [2] it was modified and extended. It includes: a radionuclide transport module, a food chain module, a module of land-to-sea transfer of radionuclides, a dose module, and a user interface. Dispersion processes for the released radionuclides are based on water exchanges from one compartment to another, adsorption on suspended sediments, depletion of suspended materials in equilibrium with the water phase activity, and re-suspension of adsorbed radionuclides through bioturbation phenomena. POSEIDON-R model includes a new dynamical uptake (food-chain) model accounting the transfer of radionuclides in marine organisms [15]. The general approach to formalize the 3D structure was implemented into the model. Two options were used to detail the situation around the release: (i) a set of "coastal boxes" that can be applied simultaneously for several regions where radioactivity enters the marine environment and (ii) flexible "local" box defined around an arbitrary accidental release point to detail situation around it. POSEIDON-R can deal with multiple timedependent sources of radionuclides, different in temporal and spatial scale. A new WWW-based userinterface was developed in IMMSP on the base of client/server technology allowing distributed calculations when client is located at one computer, and server (one server or many servers) at another computer. This Client Mode allows the installation of POSEIDON in the RODOS emergency centres as a kind of service for decision-makers. The external users can access the system via the Internet. Input model parameters as well as the results (values and pictures) are introduced in the WWW page of POSEIDON URL: http://env.immsp.kiev.ua/Modelling/Poseidon/.

\section{RESULTS OF SIMULATIONS}

The THREETOX has been applied to calculate the hydrodynamical exchange rates between the compartments in the Black Sea. A special code for calculating time-averaged flows between compartments was developed to calculate the exchange rates between the new set of horizontal and vertical boxes in the Black Sea. Hydrodynamics of the THREETOX was driven by monthly wind and air temperature. The monthly runoff rates from the Danube and Dnieper were included. The two-layer exchange in the Bosphorus was parameterised according to [16]. The model was initialised with climatological mean fields of the temperature and salinity. Grid resolution in horizontal direction was 22 by $23 \mathrm{~km}$. Vertical direction was resolved by 23 depth layers in sigma co-ordinates.

The model was used also to simulate the ${ }^{137} \mathrm{Cs}$ transport after Chernobyl accident with standard values $K_{d}{ }^{w}=K_{d}{ }^{b}=3 \mathrm{~m}^{3} / \mathrm{kg}, a_{1,2}{ }^{w}=1 \mathrm{~d}^{-1}$ and $a_{1,2}{ }^{b}=1 \mathrm{y}^{-1}$. The calculations were carried out for the 19861991 period. The initial field was the reconstructed field of ${ }^{137} \mathrm{Cs}$ in June 1986 (Fig. 3a). The results of simulations are given in Fig. 4. They showed an ability of the model to simulate complicated threedimensional fields of concentration of the radionuclides in solute, in the suspended sediments and in the bottom deposition. At the same time the calculations could be sensitive to the initial conditions, especially when patchy deposition takes place on an area between the Eastern and Western gyres of the Black Sea.

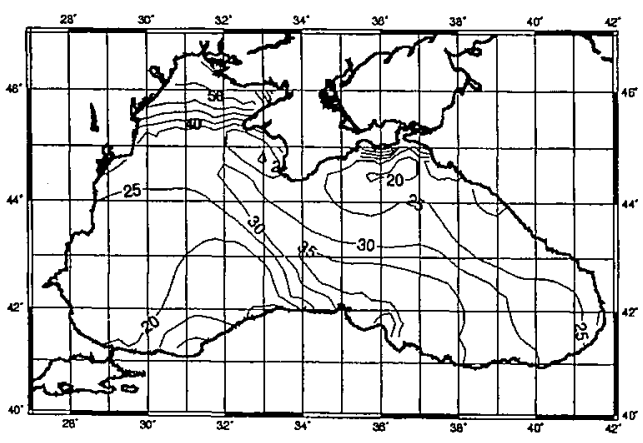

a) in bottom sediments $(\mathrm{Bq} / \mathrm{kg})$

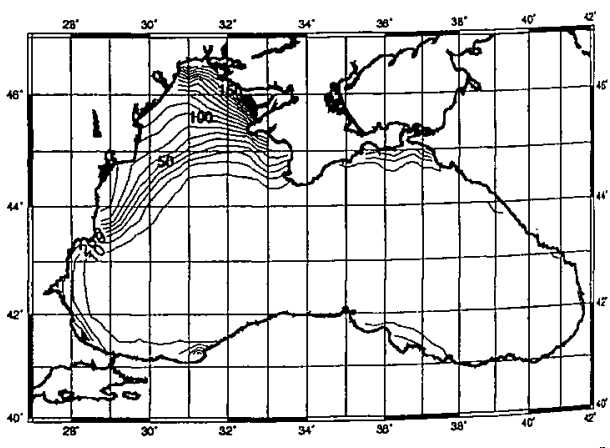

b) in bottom sediments $(\mathrm{Bq} / \mathrm{kg})$

Figure 4. Simulated by THREETOX fields of ${ }^{137} \mathrm{Cs}$ concentrations $\left(\mathrm{Bq} / \mathrm{m}^{3}\right)$ at surface in September 1988 . 
The model predicts a maximum of ${ }^{137} \mathrm{Cs}$ concentration in the center of the eastern gyre whereas measurements show more homogeneous distribution of ${ }^{137} \mathrm{Cs}$. Therefore the usage of the assimilation procedures is necessary to refine the fate of radionuclides after an accidental release.

The application of POSEIDON-R for the Black Sea - specific conditions was based on a 3D structure of water compartment. Dynamic transfers of radioactivity between compartments only occur through water and suspended sediment fluxes. Radionuclide transfer in the Black Sea was simulated in 9 boxes. They included shallow "Black Sea North-West", Azov Sea, two coastal boxes (Dnieper and Danube rivers boxes) and two deep boxes "Black Sea West" and "Black Sea East" which were divided into 3 layers on depth internals of 50 and $100 \mathrm{~m}$. Exchange coefficients between the boxes were calculated by THREETOX. The input of radionuclides in the Black Sea as atmospheric fallout and river input simulated for the period 1950 - 2000 was time dependent. The Black Sea data (1985-1991) on radionuclide concentration in the water and biota were collected and processed by NIMH [2].

The results of simulation of ${ }^{137} \mathrm{Cs}$ concentrations in the water and in the fish (non-piscivorous and piscivorous) and measured values are presented in Fig. 5-6 for Black Sea West and Black Sea East surface compartments. Recent data are obtained from [17-19]. A good agreement was found due to the 3D structure of box model and implemented dynamic food chain model.

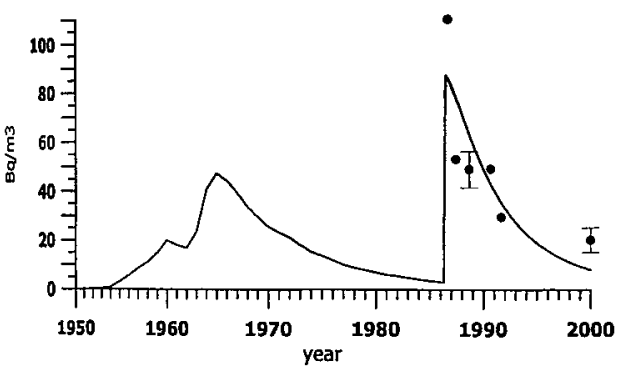

East Black Sea surface compartment

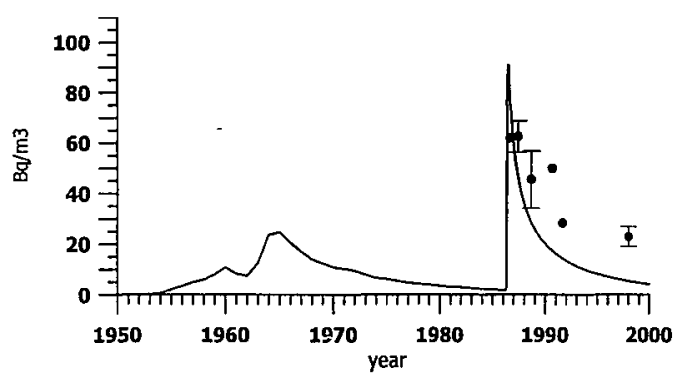

West Black Sea surface compartment

Figure 5. ${ }^{137} \mathrm{Cs}$ concentration in surface compartments vs. measurements (black circles)

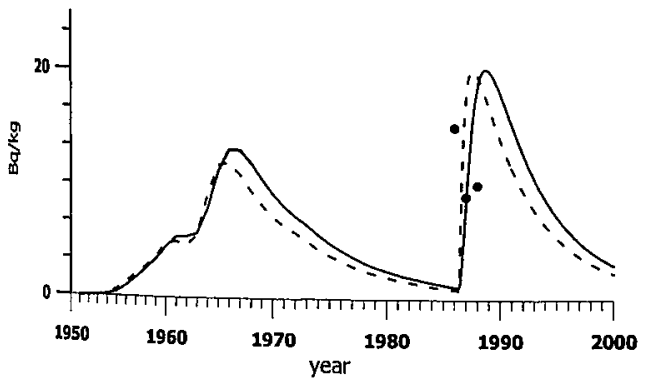

East Black Sea surface compartment

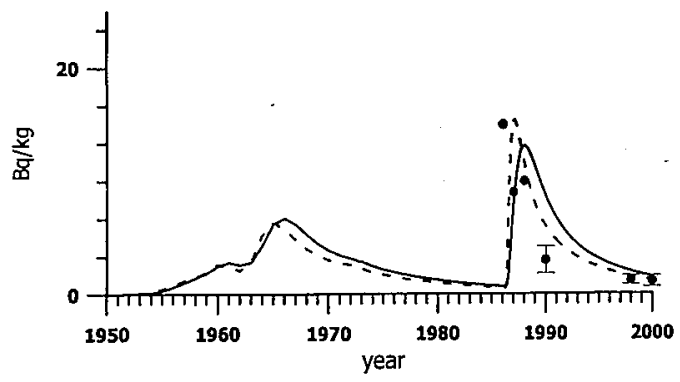

West Black Sea surface compartment

Figure 6. ${ }^{137} \mathrm{Cs}$ concentration in fish, non-piscivorous - solid line, piscivorous - dashed line, vs. measurements - black circles.

\section{CONCLUSIONS}

The Black Sea case study proves the ability of 3D compartment model POSEIDON-R to describe and predict (with some uncertainty) the transport of radionuclides in the coastal seas. The validation study Was carried out for the THREETOX model that produces water exchange rates between compartments validation validation also showed that vertical box structure is an important factor for estuary type seas as the Black Sea. The better description of the Chemobyl origin radionuclides is given in frame of the three-layer structure with thin upper layer. 


\section{Acknowledgements}

This paper is a result of co-operation under EC INCO Copernicus project IC15-CT98-0210. The encouragement and helpful discussions with Dr. R. Heling (NRG, The Netherlands), Dr. S. Lepicard (CEPN, France), Dr. M. Kolarova (NIMH, Bulgaria), Dr. A. Nikitin (FEERC, Russia) and Dr. M Zheleznyak (IMMSP, Ukraine) are highly appreciated.

\section{References}

[1] Ehrhardt J. and Weis A. (eds) EUR19144 - RODOS: Decision support system for off-site nuclear emergency management in Europe. (Office for Official Publications EC, Luxemburg 2000) 259 p.

[2] Heling R., Lepicard S., Maderich V., Shershakov V., Mungov G. and N. Catsaros, POSEIDON:A module to predict the effects of radioactive discharges in the coastal regions. Final Report, NRG, Arnhem (2000).

[3] Buesseler K.O., Livingston H.D., Casso S.A., Deep-Sea Research. 38, (2), (1991) pp.S725-S745.

[4] Stanev E.V., Staneva J.V.,Roussenov V.M. J. Marine Systems, Vol. 13, (1997)

[5] Boyer T. and Levitus S., NOAA Tech. Rep. NESDIS No. 81, (1994) 64p.

[6] Nikitin A.I., Medinets V.I., Chumichev V.B., Katrich V.M., Vakulovsky S.M., Kozlov A.I., Lepeshkin, V. Atomic Energy, 65, no. 2, (1988) pp.134-137.

[7] Nikitin A.I. ${ }^{137} \mathrm{Cs},{ }^{90} \mathrm{Sr}$ and tritium in the Black Sea. Rep. IAEA research contract 7337/RB. (1993).

[8] Polikarpov G.G., Kulebakina L.G., Timoschuk L.G., Stokozov N.A., J. Environmental Radioactivity, 13, (1991)pp.25-38.

[9] Vakulovsky S.M., Nikitin A.I., Chumichev V.B. Katrich V.M., Voitsekhovich O.A., Medinets V.I, Pisarev V.V., Bovkum L.A., Khersonsky E.S, J. Environmental Radioactivity, 23, (1994) pp. 103122.

[10] Voitsekhovich O.V., Report to IAEA CRP, IAEA RC no. 7330/R2/RB, (1995).

[11] Eremeev V.N., Ivanov L.M., Kirwan A.D., Margolina T.M., J. Environmental Radioactivity, vol.27, (1995).

[12] Margvelashvili N., Maderich V., and Zheleznyak M THREETOX - a computer code to simulate three-dimensional dispersion of radionuclides in stratified water bodies. Radiation Protection Dosimetry, 73, .(1997) pp. 177-180

[13] Blumberg A.F. and Mellor G.L., in Three-Dimensional Coastal Ocean Models, edited by N. Heaps, Am. Geoph. Union, (1987) p.208.

[14] Lepicard S., Raffestin D., Rancillac F., Radiation Protection Dosimetry, 75, (1998) pp 79-83.

[15] Heling R., Koziy L. and Bulgakov V., A dynamical approach for the uptake of radionuclides in marine organisms for the POSEIDON-R model system. This issue.

[16] Maderich V., Konstantinov S. Seasonal dynamics of the system sea-strait: Black Sea-Bosphorus case study. Estuarine, Coastal and Shelf Sciences (2001) (accepted).

[17] 1998 Cruise Rep. of IAEA TCP RER/2/003 "Marine environmental Assessment of the Black Sea Region", (working document)

[18] 2000 Cruise Rep. of IAEA TCP RER/2/003 "Marine environmental Assessment of the Black Sea Region", (working document)

[19] IAEA TCP RER/2/003 Annual Progress Reports of Ukraine, Turkey, Romania, Bulgaria.1998-2000. (Working documents) 